\title{
Behavioral and pharmacological influences on phencyclidine discrimination in the pigeon
}

\author{
DONALD E. McMILLAN \\ University of Arkansas for Medical Sciences, Little Rock, Arkansas
}

\begin{abstract}
Discriminative stimuli produced by drugs control behavior in the same way as exteroceptive discriminative stimuli control behavior, despite the difficulty in controlling the intensity of the discriminative stimulus properties of drugs throughout test sessions. In recent years, many investigators have correlated the potency of drugs as discriminative stimuli, with their affinity for specific pharmacological receptors. High correlations have been interpreted as evidence that the discriminative stimulus properties of drugs are mediated by these specific pharmacological receptors. However, the relationship between discriminative stimulus potency and receptor affinity can be confounded by other pharmacological effects of drugs, such as their ability to produce position responding, and by behavioral variables, such as the schedule of reinforcement under which the drug discrimination is established and measured.
\end{abstract}

Almost 50 years ago, Girden and Culler (1937) demonstrated that a drug can function as a discriminative stimulus to control responding. Since that time, the study of discriminative stimulus properties of drugs has become a very active area of research in behavioral pharmacology, with broad implications. For example, if the discriminative-stimulus properties of a drug are also positively reinforcing, these properties may contribute to the abuse potential of the drug. Conversely, discriminativestimulus properties of drugs that function as negative reinforcers may lead to problems in compliance with medication schedules.

In most experiments, drug discrimination has been established by differentially reinforcing responding in the presence and absence of the drug stimulus. For example, in a typical design, animals might be reinforced for responses on one lever if a drug has been administered before the session, and reinforced for responses on a different lever if saline solution has been administered before the session. The only discriminative stimulus available to control responding is the presence or absence of the internal stimuli (interoceptive stimuli) generated by the pharmacological effects of the drug. Once discrimination between the drug state and the nondrug state is established, a number of interesting questions can be asked. For example, does responding controlled by the drug state generalize to other doses of the training drug? What is the minimum dose of the training drug that will produce responding on the drug-associated lever? Does responding on the drug lever generalize to other drugs that might be substituted for the training drug, and, if so, do these

Presented at the Seventh Harvard Symposium on Quantitative Analyses of Behavior: Biological Determinants, Harvard University, June $8-9,1984$. Preparation of this review was supported by NIDA Grant DA 02251. The author's mailing address is University of Arkansas for Medical Sciences, 4301 W. Markham St., Little Rock, AR 72205-7199. other drugs share pharmacological actions with the training drug?

Although these drug-discrimination experiments appear to be straightforward, there are numerous difficulties in drug-discrimination experiments that are not frequently encountered in experiments on stimulus control by exteroceptive stimuli. If a conditional discrimination is established using such exteroceptive discriminative stimuli as the presence or absence of a light, so that when the light is on responses will be reinforced on one lever and when the light is off responses will be reinforced on the other lever, the condition of the light is completely under the control of the experimenter. However, when a drug is administered by intramuscular, intraperitoneal, or oral routes, the absorption and distribution of the drug is slow and sometimes irregular, so that the onset of the interoceptive stimuli is gradual and sometimes unpredictable. Furthermore, the exteroceptive light stimulus can be presented and removed repeatedly during a session, permitting differential reinforcement to occur repeatedly under both stimulus conditions. This is clearly not so in most drug-discrimination experiments, where, after the drug is administered, it is in the organism and the "no-drug response" cannot be reinforced again until the drug has been metabolized and/or excreted. Finally, the intensity of an exteroceptive stimulus, such as a light, presumably undergoes little change throughout a session, while the interoceptive drug stimulus waxes and wanes with the increasing and decreasing concentrations of the drug at the sites in the body producing the interoceptive stimuli.

Despite these general problems, a large number of studies conducted during the past few years have been directed toward describing the pharmacology of drug discrimination. It has been suggested that drugs may be classified on the basis of their discriminative-stimulus properties (Weissman, Milne, \& Melvin, 1982), and it has even been implied that drugs to which responding generalizes 
from the training drug may interact with the same pharmacological receptors as the training drug (Cone, McQuinn, \& Shannon, 1984; Friedman, Barrett, \& Sanders-Bush, 1984; Young, Stephens, Hein, \& Woods, 1984).

There are a number of assumptions underlying such interpretations. After a drug has been administered, the drug must be taken up from its site of administration and be distributed to those sites where its pharmacological effects give rise to the interoceptive stimuli attended to by the animal. The fact that a drug produces discriminative stimuli does not necessarily imply that a specific group of pharmacological receptors has been activated, or even that specific receptors in the pharmacological sense have been activated. Furthermore, the drug will also produce a variety of pharmacological effects, some of which do not contribute to the interoceptive-stimulus complex. Drugs have multiple effects, and some effects are part of an interoceptive-stimulus complex to which an animal can attend, but some are not.

To study the discriminative-stimulus properties of drugs, the investigators must demonstrate that behavior comes under the control of the interoceptive-stimulus complex produced by the drug. Unfortunately, the interpretation of the data generated by such experiments can be confounded by the drug's other effects on behavior. Many factors have been found to influence the effect of a drug on behavior, including the schedule of reinforcement maintaining the behavior, the rate and pattern of responding maintained by the schedule, the degree of stimulus control, the behavioral history of the organism, and so forth (Kelleher \& Morse, 1968; Laties, 1975; McKearney, 1979; McMillan \& Leander, 1976).

The logical consequences of these multiple drug effects in drug-discrimination experiments are that, when one tests for response generalization from the training drug to a new drug, the degree of response generalization obtained may be a reflection not only of the degree to which the discriminative-stimulus properties of the training drug and of the substitution drug overlap, but also of the effects of the drug on other complex behavioral processes involved when the animal "reports" on the discriminativestimulus control maintained by the substitution drug in a drug-discrimination study (Appel \& Dykstra, 1977). For example, the discriminative-stimulus properties of a training drug and another drug may be nearly identical. Yet, if the substitution drug has the additional pharmacological effect of greatly increasing response variability, some stimulus control may appear to be lost, but not because of differences in the discriminative stimulus properties of the two drugs. Under such circumstances, the task of the behavioral pharmacologist is to separate the discriminativestimulus properties from the drug's other effects on behavior.

During the past several years, interest has developed in the role of behavioral variables in drug discrimination. Toward this end, a color-tracking procedure for the pigeon has been developed under which the bird is trained to track the location of one color if a given drug has been ad- ministered before the session and to track the location of another color if saline has been administered before the session (McMillan, Cole-Fullenwider, Hardwick, \& Wenger, 1982). The details of the procedure are shown in Figure 1. Initially, the pigeon is required to make an observing response on a white center key. Following the observing response, the side keys are lighted, one with red and one with green color. Responses on the red key eventually were reinforced when $1.5 \mathrm{mg} / \mathrm{kg}$ phencyclidine had been administered before the session, and responses on the green key eventually were reinforced when saline solution had been administered before the session. Completion of a small fixed ratio at either key color again lighted the observing key. The birds were required to complete a fixed number (e.g., 10) of fixed ratios at the "correct" key color before the food reinforcer was made available. Location of the red and green key colors varied randomly on the side keys after each observing
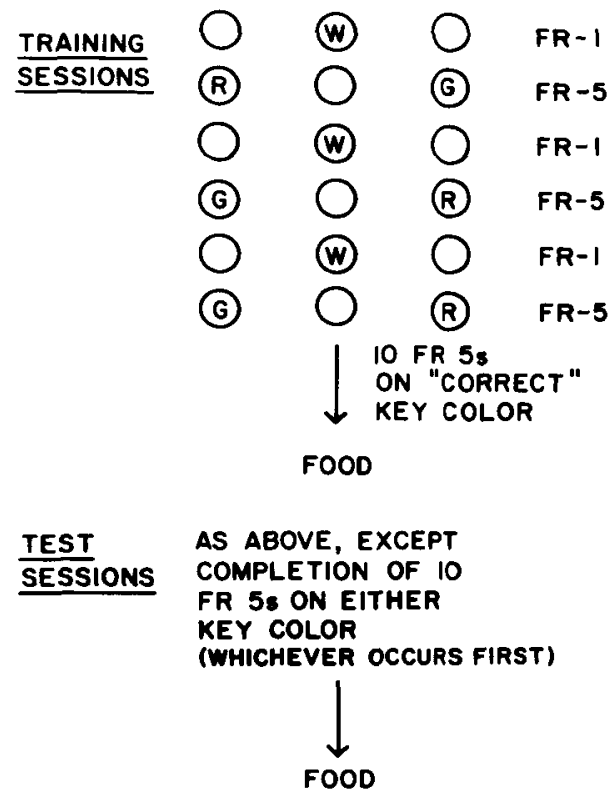

Figure 1. Schematic diagram of training sessions for discrimination of phencyclidine stimuli from saline. The circles represent response keys. Abbreviations are as follows: W, white key; $G$, green key; $R$, red key; no symbol in circle, unlighted key; $F R$, fixed-ratio schedule of reinforcement. At the beginning of the session, the center key is lighted with a white light and the side keys are dark. One peck on the center key (FR 1) turns off the center key and lights the side keys, one with a green light and one with a red light. Five pecks (FR 5) on either side key return the white light to the center key and extinguish the side-key lights, Completion of $10 \mathrm{FR}$ 5s on the "correct" key produces food. The "correct" key is the red key when $1.5 \mathrm{mg} / \mathrm{kg}$ phencyclidine has been administered before the session, and the green key when saline has been administered before the session. During test sessions, completion of $10 \mathrm{FR} 5 \mathrm{~s}$ on either key color produced food. The position of the red and green key lights on the side keys varied randomly each time a peck on the center key lighted the side keys. During generalization experiments, when other doses of phencyclidine and other drugs were substituted for the training dose of phencyclidine, a cumulative-dosing procedure was used (McMillan, 1982). 


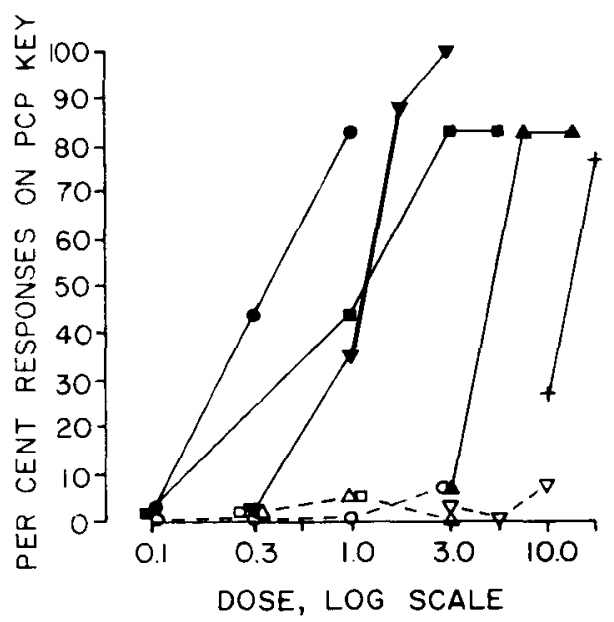

Figure 2. Cumulative dose-ffect curves for phencyclidine and other drugs substituted for the training dose of phencyclidine. Abscissa: $\mathrm{mg} / \mathrm{kg}$ dose, $\log$ scale. Ordinate: percentage of total ratios completed on the phencyclidine (red) key. Each point is a mean of single observations in 5 birds. Symbols are as follows: $\bullet$, phencyclidine; $\Delta$, ketamine; $\nabla, l$-cyclazocine; $\square, d$-cyclazocine; + , pentobarbital; $O, d$-amphetamine; $\Delta$, morphine; $\nabla, d$-methadone; $\square$, l-methadone.

response. This second-order schedule requiring observing responses generated a large number of responses before the delivery of a food reinforcer occurred, serving as an additional cue as to which response would be reinforced on subsequent trials (Jenkins, 1965). Under this procedure, pigeons that receive $1.5 \mathrm{mg} / \mathrm{kg}$ phencyclidine before the session respond almost entirely on the red key, and pigeons receiving saline before the session respond almost entirely on the green key.

Figure 2 shows the results of testing for response generalization to other doses of the training drug and to other drugs substituted for phencyclidine. There was response generalization to other doses of phencyclidine, to a chemical congener (ketamine), to both optical isomers of cyclazocine, and perhaps to pentobarbital. On the other hand, response generalization to saline, $d$-amphetamine, morphine, $d$-methadone, and $l$-methadone did not take place (McMillan, 1982). The generalization from phencyclidine to ketamine, a drug with many pharmacological similarities, is not unexpected (Jarbe, Johanson, \& Henriksson, 1975). There have also been suggestions that benzomorphans, such as cyclazocine, may act on the same receptor as phencyclidine (Cone et al., 1984). Although there are no strong theoretical reasons why there should be response generalization from phencyclidine to pentobarbital, other investigators have also observed this phenomenon (Overton, 1975).

Figure 3 shows a clear example of the manner in which other behavioral effects of a drug can influence stimulus control in drug-discrimination experiments. The figure plots the tendency of birds to respond at a position (preferred key) against the tendency to respond to a color (red key). Figure 2 suggested that some response gener- alization occurs from phencyclidine to pentobarbital. Birds trained to discriminate phencyclidine from saline, when given high doses of pentobarbital, responded largely on the PCP key, but the percentage of responding on the drug-associated key never quite reached the level seen with the training drug. Figure 3 shows that when these pigeons respond nearly equally on red and green keys after barbiturates are administered, such responding is confined almost completely to one key position (e.g., the key position controls responding rather than the key color) (McMillan \& Wenger, 1983). It seems unlikely that such position responding is representative of the degree of overlap of the discriminative-stimulus complex produced by phencyclidine with that produced by pentobarbital. A more reasonable explanation is that pentobarbital has produced position responding, which interferes with the stimulus control exerted by the association of the drug and nondrug stimuli with the respective key colors.

In studies of drug effects on discrimination behavior, the methods of signal detection derived from information theory have proved to be valuable tools (Appel \& Dykstra, 1977). These techniques have been used to analyze drug-discrimination data in an effort to separate discriminability of the interoceptive stimulus from other factors that might bias responding away from control by the drug stimulus (McMillan \& Wenger, 1984).

In these experiments, the schedule of reinforcement was used to bias responding toward or away from making the drug response. Pigeons were biased toward responding on the red (drug-associated) key through reinforcement of responding on the red key under a second-order fixedratio 5 (fixed-ratio 5) schedule and were biased away from responding on the green (saline-associated) key under a second-order fixed-ratio 25 (fixed-ratio 5) schedule. Sub-

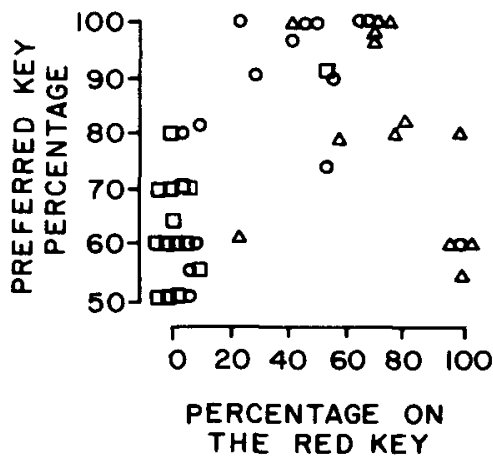

Figure 3. Anslysis of position responding. Abscissa: percentage of total ratios completed on the red (phencyclidine) key after various doses of pentobarbital under several second-order schedules of reinforcement. Ordinate: percentage of total responses on the preferred key (defined as that key on which $50 \%$ or more of the total responses were made). Each point represents a single observation for one bird. Symbols are as follows: $\bullet, 3 \mathrm{mg} / \mathrm{kg}$ pentobarbital; $O, 10 \mathrm{mg} / \mathrm{kg}$ pentobarbital; $\Delta, 17.5 \mathrm{mg} / \mathrm{kg}$ pentobarbital. When birds made from $30 \%$ to $70 \%$ of their responses on the phencyclidine key, more than $90 \%$ of these responses were made at a particular key location (e.g., left or right key). 
sequently, these schedules were reversed in order to reverse the bias. These data (for phencyclidine, pentobarbital, and $d$-amphetamine) are shown in Figure 4 .

The first column in the top row of Figure 4 shows that, when responding was biased toward the phencyclidine key by the schedule of reinforcement (filled points), the phencyclidine dose-effect curve fell to the left of the curve obtained when responding was biased toward the saline key (unfilled points). Thus, biasing responding with the schedule of reinforcement was successful. The second and third rows of column 1 show changes in the point estimate of discrimination and bias (McMillan \& Wenger, 1984) with dose. At low doses of phencyclidine, discriminability of the interoceptive stimulus is low and responding is controlled largely by bias. As the dose of phencyclidine increases, discriminability increases and bias decreases (moves toward zero from a negative value). At intermediate doses of phencyclidine (e.g., 0.56 to $1.0 \mathrm{mg} / \mathrm{kg}$ ), some birds exhibit considerable position responding (Figure 4, bottom row), which may contribute to the decrease in bias.

The second column of Figure 4 shows a similar analysis for pentobarbital. When responding was biased toward the phencyclidine key by the schedule of reinforcement, the dose-effect curve for pentobarbital fell above the dose-effect curve for pentobarbital when responding was biased toward the saline key. Analysis of the point estimates of bias and discriminability showed that discriminability did not increase with increasing doses of pentobarbital to the same extent as occurred with increasing doses of phencyclidine, nor was there a clear tendency for increasing doses of pentobarbital to decrease bias. At $10 \mathrm{mg} / \mathrm{kg}$ pentobarbital, most birds showed strong position responses, making more than $85 \%$ of their responses on one key. Analysis of the data in Figure 4 suggest that the interoceptive stimuli produced by pentobarbital were not particularly discriminable as being "phencyclidinelike" and that the primary factor determining the differences in responding were bias and position responding.

The last column of Figure 4 shows the same type of analysis for $d$-amphetamine. Although the dose-effect curve for $d$-amphetamine, when responding was biased toward phencyclidine by the schedule, fell above the $d$-amphetamine dose-effect curve when responding was biased toward saline, the birds did not respond predominately on the phencyclidine key after $d$-amphetamine. Analysis of the point estimates of discrimination and bias show that the birds were controlled by bias and not by similarities in the interoceptive-stimulus complexes produced by $d$-amphetamine and phencyclidine.

The results of these experiments suggest that the schedule of reinforcement can shift generalization gradients when drugs are used as discriminative stimuli. The application of signal-detection techniques and positionpreference analyses to these drug-discrimination studies enabled the partial separation of drug-stimulus discriminability from other factors. For example, low doses of PCP were not discriminable, and responding was controlled by response bias. As the dose of phencyclidine increased (as the stimulus intensity increased), discriminability in- creased and bias decreased. At intermediate doses of PCP, key position was a major determinant of what key would be pecked. For pentobarbital, bias and key position continued to control responding, but there was less ten-
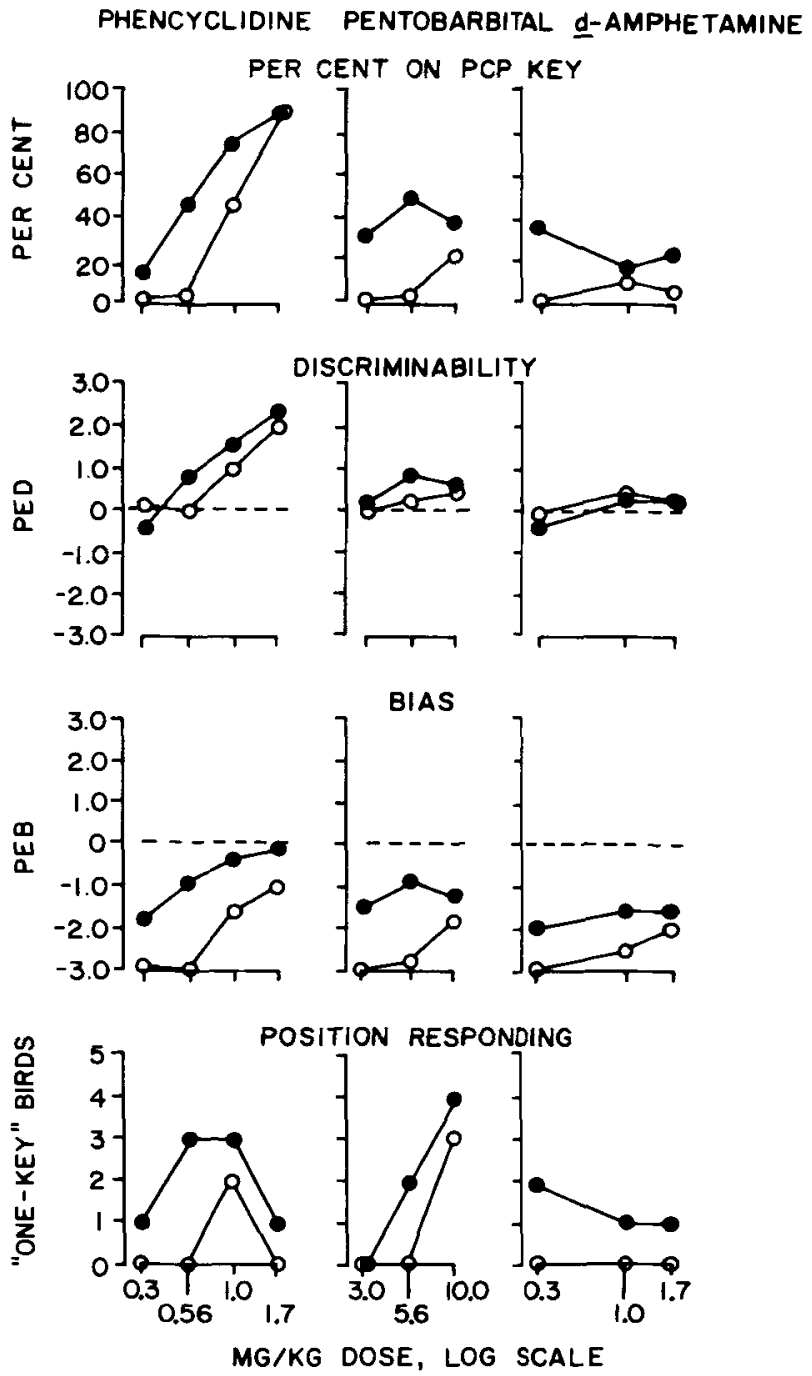

Figure 4. Analysis of responding when the schedule of reinforcement was used to bias responding toward the phencyclidine key [during training sessions, responses on the red key were reinforced under FR 5 (FR 5) if phencyclidine was given before the session, and under FR 25 (FR 5) if saline was given before the session] or toward the saline key [during training sessions, responses on the green key were reinforced under FR 5 (FR 5) if saline was given before the session, and under FR 25 (FR 5) if phencyclidine was given before the session]. The filled points show cumulative dose-effect curves for phencyclidine bias and the unfilled points show cumulative doseeffect curves for saline bias. The first column shows phencyclidine data, the second column pentobarbital data, and the third column $d$-amphetamine data. The top row shows the percentage of total ratios completed on the phencyclidine (red) key. The second row shows the point estimate of discrimination. The third row shows the point estimate of bias. The final row shows the number of pigeons making more than $85 \%$ of their responses at one of the key positions (as oppoeed to color tracking). Each point represents a mean of single observations in each of 5 birds, except for the final row, where each point refers to the number of birds making a position response. 
dency for discriminability to increase with dose. For $d$-amphetamine, there was little tendency for the interoceptive stimuli produced to be discriminated as phencyclidine; responding was controlled primarily by bias. The results of these experiments emphasize that drug discriminations, like other discriminations, are complex behavioral processes that can be affected by a number of behavioral variables. Failure to consider the role of such behavioral variables can lead to misinterpretations of the data in drug-discrimination experiments.

\section{REFERENCES}

APPEL, J. B., \& DyKsTra, R. A. (1977). Drugs, discrimination and signal detection theory. In T. Thompson and P. B. Dews (Eds.). Advances in Behavioral Pharmacology, (Vol. 1, pp. 139-166). New York: Academic Press.

Cone, E. J., MCQuinn, R. L., \& Shannon, H. E. (1984). Structureactivity relationship studies on phencyclidine derivatives in rats. Journal of Pharmacology \& Experimental Therapeutics, 228, 147-153.

Friedman, R. L., Barrett, R. J., Sanders-Bush, E. (1984). Discriminative stimulus properties of quipazine: Mediation by serotonin binding sites. Journal of Pharmacology \& Experimental Therapeutics, 228, 628-635.

Girden, E., \& Culler, E. (1937). Conditioned responses in curarized striate muscles in dogs. Journal of Comparative Psychology, 23, 261-274.

Jarbe, T.U.C., Johanson, J. O., \& Henriksson, B. G. (1975). Drug discrimination in rats: The effects of phencyclidine and ditran. Psychopharmacologia, 42, 33-39.

JENKINS, H. M. (1965). Measurement of stimulus control during discriminative operant conditioning. Psychological Bulletin, 64, 365-376.

Kelleher, R. T., \& Morse, W. H. (1968). Determinants of the specificity of behavioral effects of drugs. Ergebnisse der Physiologie, Biolo gischen Chemie und Experimentellen Pharmakologie, 60, 1-56.

Laties, V. G. (1975). The role of discriminative stimuli in modulating drug action. Federation Proceedings, 34, 1880-1888.
MCKeARNEY, J. W. (1979). Interrelations among prior experience and current conditions in the determination of behavior and the effects of drugs. In T. Thompson and P. B. Dews (Eds.), Advances in Behavioral Pharmacology, (Vol. 2, pp. 39-64). New York: Academic Press.

MCMillan, D. E. (1982). Generalization of the discriminative stimulus properties of phencyclidine to other drugs in the pigeon using color tracking under second order schedules. Psychopharmacology, 78, 131-134.

McMillan, D. E., Cole-Fullenwider, D. A., Hardwick, W. C., \& Wenger, G. R. (1982). Phencyclidine discrimination in the pigeon using color tracking under second-order schedules. Journal of the Experimental Analysis of Behavior, 37, 143-147.

MCMillan, D. E., \& Leander, J. D. (1976). Modification of baseline operant behavior by drugs. In S. D. Glick and J. Goldfarb (Eds.), Behavioral pharmacology (pp. 85-139). St. Louis, MO: Mosby.

MCMillan, D. E., \& Wenger, G. R. (1983). Effects of barbiturates and other sedative hypnotics in pigeons trained to discriminate phencyclidine from saline. Journal of the Experimental Analysis of Behavior, 40, 133-142.

McMillan, D. E., \& Wenger, G. R. (1984). Bias of phencyclidine discrimination by the schedule of reinforcement. Journal of the Experimental Analysis of Behavior, 42, 51-66.

OVERTON, D. A. (1975). A comparison of the discriminable CNS effects of ketamine, phencyclidine and pentobarbital. Archives Internationales de Pharmacodynamie et de Therapie, 215, 180-189.

Weissman, A., Milne, G. M., \& Melvin, L. S., Ir. (1982). Cannabimimetic activity from $\mathrm{CP}-47,497$, a derivative of 3-phenylcyclohexanol. Joumal of Pharmacology \& Experimental Therapeutics, 222, 516-523.

Young, A.M., Stephens, K. R., Hein, D. W., \& Woods, J. H. (1984). Reinforcing and discriminative stimulus properties of mixed agonistantagonist opioids. Journal of Pharmacology \& Experimental Therapeutics, 229, 118-126.

(Manuscript received January, 1985; revision accepted for publication June $17,1987$. ) 